\title{
Autopsy-certified maternal mortality at Ile-Ife, Nigeria
}

This article was published in the following Dove Press journal:

International Journal of Women's Health

3I December 2013

Number of times this article has been viewed

\author{
Amatare Dinyain' \\ G Olutoyin Omoniyi-Esan ${ }^{2}$ \\ Olaejirinde O Olaofe ${ }^{3}$ \\ Donatus Sabageh ${ }^{3}$ \\ Akinwumi O Komolafe ${ }^{2}$ \\ Olusegun S Ojo² \\ 'Department of Anatomic Pathology, \\ Niger Delta University Teaching \\ Hospital, Okolobiri, Bayelsa State, \\ Nigeria; ${ }^{2}$ Department of Morbid \\ Anatomy and Forensic Medicine, \\ Obafemi Awolowo University, Ile-Ife, \\ Osun State, Nigeria; ${ }^{3}$ Department of \\ Morbid Anatomy and Histopathology, \\ Ladoke Akintola University of \\ Technology, Ogbomoso, Oyo State, \\ Nigeria
}

Aim: Maternal mortality is a major health problem, especially in Nigeria, where accurate autopsy-based data on the prevalent causes are not readily available. The aim of this study was therefore to accurately determine the causes of maternal death as seen in a tertiary health facility in Nigeria.

Materials and methods: This was a descriptive, retrospective review of the postmortem autopsy findings from cases of maternal death at the Obafemi Awolowo University Teaching Hospitals Complex, Ile-Ife, Nigeria over a 5-year period. Analyses were performed for differences in proportions using PEPI computer programs for epidemiologists $(P$ is significant at $<0.05$ )

Results: A total of 84 cases of maternal deaths were used for the study. Approximately $71.4 \%$ of the maternal deaths were due to direct causes and $28.6 \%$ were due to indirect causes. The mean age at the time of death was $27.9 \pm 7.5$ years. Overall, the three leading causes of death were obstetric hemorrhage (30.9\%), complications of abortion (23.8\%), and nongenital (nonobstetric) infections (14.2\%). Of the direct causes of maternal death, obstetric hemorrhage (43.3\%) was the leading cause, with postpartum hemorrhage accounting for most (65.0\%) of such deaths; other causes included complications of unsafe induced abortion (33.3\%) and of labor (11.7\%). Of the indirect causes, nongenital infections $(50.0 \%)$, anemia $(25.0 \%)$, and preexisting hypertension (20.8\%) accounted for the majority of the maternal deaths. There was disparity between the clinical and autopsy diagnoses in 34 of the 84 cases (38.1\%).

Conclusion: The leading causes of maternal death in this study are similar to those in other developing countries. Autopsy is an invaluable tool in accurately determining the cause of maternal death.

Keywords: autopsy, causes, maternal mortality, Nigeria

\section{Introduction}

Approximately 250,000 African women are said to die yearly during pregnancy, delivery, or the puerperium. Maternal deaths in Nigeria contribute significantly to this number. ${ }^{1}$ In fact, data from the United Nations and the World Bank have identified Nigeria as one of the worst places in the world for a woman to give birth, with about 59,000 women dying every year due to pregnancy-related complications. ${ }^{2}$ The average maternal mortality rate in Nigeria is estimated to be about 704 deaths per 100,000 live births, although this number ranges from about 165 deaths per 100,000 live births in the southwest region to 1,549 deaths per 100,000 live births in the northeastern subregions of the country. ${ }^{2}$ These unacceptably high rates have prompted the Nigerian government to join the international community in adopting
Correspondence: Olutoyin Omoniyi-Esan Department of Morbid Anatomy and Forensic Medicine, Obafemi Awolowo University, lle-lfe, Osun State, Nigeria Tel +2348033536852 Email goesan@oauife.edu.ng, gomoniyi_ esan@yahoo.com 
the Millennium Development Goal of reducing maternal mortality rate by $75 \%$ by the year 2015 . Although many policies and programs have been put in place over the years to achieve this goal, the results have been less than optimal, possibly because they have been driven by limited scientific information, most of which has been obtained from clinical records and verbal autopsies. ${ }^{3-5}$

The role of the autopsy as a tool in the prevention and reduction of maternal deaths has been well-documented, especially in developed countries where maternal mortality rates are now so low that perinatal death rates are more appropriately used as an index of the state of the health system. In such countries, thorough postmortem examinations are regularly conducted as part of confidential inquiries into maternal deaths, with reports being published at regular intervals. ${ }^{6}$

Information provided by medical autopsies is known to increase the accuracy of cause of death reports, even in cases where the cause of death can be wholly based on clinical evaluation. ${ }^{7-10}$ Maternal autopsies are thus required for accurate death certification, determination of the underlying causes of death, and establishment of maternal mortality rates. ${ }^{6}$ These are invaluable tools for reducing and preventing maternal deaths.

In accordance with recommendations from the Safe Motherhood Conference held in Abuja in 1990, the Federal Government of Nigeria has directed that confidential inquiries be conducted for maternal deaths in Nigeria (with the autopsy as a pivotal tool) and that regular reports be made to the Federal Ministry of Health. ${ }^{6}$ This has led to an increase in the demand for maternal autopsies at the Obafemi Awolowo University Teaching Hospitals Complex, Ile-Ife, Nigeria (OAUTHC), a referral tertiary health care facility located in the southwestern region of Nigeria.

The aim of this study was to review the autopsy findings from postmortem examinations conducted on cases of maternal mortality at the OAUTHC tertiary health facility, in order to accurately determine the causes of maternal death prevalent in our environment.

\section{Materials and methods}

This was a descriptive retrospective study of the autopsy findings from postmortem examinations conducted on cases of maternal mortality in the Department of Morbid Anatomy and Forensic Medicine, OAUTHC, between January 1, 2005 and December 31, 2009. The cases selected for the study were those that satisfied the World Health Organization definition of maternal death. ${ }^{11}$ Data for this study were obtained from the departmental autopsy records and register as well as from the patient's clinical notes. Information such as the patient's age, parity, occupation, gestational age, mode of delivery, clinical diagnosis, and anatomical diagnosis was extracted. At the OAUTHC, all cases of pregnancy-related deaths are referred to the Department of Morbid Anatomy and Histopathology for a full postmortem autopsy (which includes both macroscopic examination and histologic evaluation of all viscera, using standardized protocols), the results of which are relayed to the Federal Ministry of Health as part of a confidential inquiry into maternal deaths.

All cases of maternal death were classified as having either direct or indirect causes, on the basis of the specific anatomical diagnosis. The specific anatomical diagnoses with respect to direct maternal deaths were further classified as: 1) obstetric hemorrhage (including abruptio placentae, placenta previa, uterine atony, ruptured ectopic pregnancy, retained products of conception, uterine rupture, etc); 2) complications of labor (including puerperal sepsis, aspiration pneumonitis); or 3) complications of unsafe abortion (including sepsis, uterine perforation, hypovolemic shock). Indirect causes of maternal deaths were classified as anemia, neoplasms, preexisting hypertension, and nongenital infections (including pyogenic and tuberculous meningitis, pulmonary tuberculosis, broncho/lobar pneumonia). In cases where the clinical diagnosis was usually sufficiently accurate (eg, eclampsia), specific autopsy findings were sought to corroborate the clinical diagnosis.

The patients were also grouped into different parity groups: never given birth (Nullipara); given birth one time (Para 1); given birth two, three, or four times (Para 2-4); given birth more than four times ( $>$ Para 4 ). These parity groups were compared with the various causes of maternal death.

The data obtained was analyzed using Computer Programs for Epidemiologists (PEPI). ${ }^{12}$ Univariate analysis was carried out and the causes of maternal deaths were presented in frequencies and percentages. Chi-square analysis was performed with the $P$-value set at 0.05 .

Ethical approval for this study was obtained from the OAUTHC Ethics and Research Committee.

\section{Results}

During the 5-year period under review, a total of 1,969 autopsies were performed in the OAUTHC Department of Morbid Anatomy and Forensic Medicine. A total of 128 maternal deaths occurred during 7,472 live births during this period, resulting in a maternal mortality rate of 1,713 per 100,000 live births. Autopsies were conducted on 102 (5.2\% of all 
done in the department) of the 128 maternal deaths, resulting in an autopsy rate of 79.7\%. However, only 84 (82.4\%) cases had complete clinical and autopsy information relevant for this study and were thus included in the study. No differences were observed with regards to age between those included and those excluded due to incomplete clinical and/ or autopsy information.

Overall, there were $60(71.4 \%)$ direct causes and $24(28.6 \%)$ indirect causes of maternal deaths. The leading causes of direct maternal deaths were obstetric hemorrhage (26 cases, 43.3\%), complications of abortion (20 cases, $33.3 \%$ ), complications of labor (seven cases, 11.7\%) and preeclampsia/eclampsia (seven cases, 11.7\%). Half of indirect maternal deaths were due to nongenital infections and $25 \%$ were due to severe anemia in pregnancy (Tables 1 and 2).

In an examination of maternal deaths by age, the age range was $15-45$ years (mean $27.9 \pm 7.5$ years), with the $25-29$ years and the 35-39 years age groups each accounting for $23.8 \%$ of cases (Table 1 ). More than two-thirds of all maternal deaths were due to obstetric hemorrhage (30.9\%), complications of abortion $(23.8 \%)$, or infection in organs outside the genital tract $(14.2 \%)$. Most of the deaths from obstetric hemorrhage occurred in the 25-29 years and 35-39 years age groups, accounting for $34.6 \%$ and $26.9 \%$ of these cases, respectively. About $40 \%$ of maternal deaths due to complications of abortion occurred in the 20-24 years age group.

In an examination of maternal deaths by pregnancy stage, most $(57.1 \%)$ causes of maternal death occurred during the third trimester, delivery, and puerperium (Table 2). Secondtrimester deaths (29.8\%) were mainly due to complications of abortion, nongenital infections, obstetric hemorrhage, and anemia. A statistically significant relationship was found between the timing of pregnancy and direct causes of maternal death $(P<0.001)$. Overall, $33.3 \%$ of maternal deaths were due to infectious diseases (puerperal sepsis, postabortion sepsis, and nongenital infections).

Among the 26 cases of obstetric hemorrhage, 17 (65.4\%) occurred postpartum and nine (34.6\%) occurred antepartum (Table 3). About $66.7 \%$ of antepartum hemorrhages were due to abruptio placentae. On the other hand, about $76.4 \%$ of postpartum hemorrhages were due to uterine atony. Uterine atony occurred only in Nullipara (15.4\%) and Para 3 (86.6\%) women. Other causes were ruptured or perforated uterus $(11.8 \%)$ and retained placenta $(11.8 \%)$. Of the seven cases arising from complications of labor, five (71.4\%) were due to puerperal sepsis and two $(28.6 \%)$ were due to aspiration pneumonitis. Complications of abortion were predominantly due to postabortion sepsis $(55.0 \%)$, severe hemorrhage $(25.0 \%)$, and uterine perforation $(20.0 \%)$. All deaths from complications of abortion occurred in the first $(45.0 \%)$ and second (55.0\%) trimesters of pregnancy (Table 2). According to Figure 1, obstetric hemorrhage and complications of labor were more common among Para 2-4 individuals, whereas the complications of abortion and preeclampsia/eclampsia were more common in Nullipara women. These observations were found to be statistically significant $(P<0.009)$.

Anemia in pregnancy was mainly nutritional, with only one case due to sickle-cell disease. Death resulted from anemic heart failure in all of these cases. Deaths due to nongenital infections were bacterial in origin and included pyogenic meningitis (41.7\%), pulmonary tuberculosis $(25.0 \%)$, pneumonia $(25.0 \%)$, and tuberculous meningitis $(8.3 \%)$. Deaths resulting from the complications of preexisting essential hypertension were due to malignant hypertension $(40.0 \%)$, left ventricular failure $(40.0 \%)$, and intracranial hemorrhage $(20.0 \%)$.

There was disparity between the clinical and autopsy diagnoses in 34 of the 84 cases (38.1\%). In such cases, the final autopsy diagnoses were nongenital infections (23.5\%),

Table I Distribution of the causes of maternal death by age

\begin{tabular}{|c|c|c|c|c|c|c|c|c|c|}
\hline \multirow[t]{2}{*}{ Category } & \multirow[t]{2}{*}{ Cause } & \multicolumn{8}{|c|}{ Age group (years), $n$} \\
\hline & & $15-19$ & $20-24$ & $25-29$ & $30-34$ & $35-39$ & $40-44$ & $45-49$ & $\mathbf{N}(\%)$ \\
\hline Direct (obstetric) & Obstetric hemorrhage & I & 2 & 9 & 4 & 7 & 3 & 0 & $26(30.9)$ \\
\hline \multirow[t]{3}{*}{ causes } & Complications of abortion & 5 & 8 & 2 & 3 & 2 & 0 & 0 & $20(23.8)$ \\
\hline & Preeclampsia/eclampsia & 2 & I & 3 & 0 & I & 0 & 0 & $7(8.3)$ \\
\hline & Complications of labor & I & 0 & I & 3 & I & 0 & I & $7(8.3)$ \\
\hline Indirect (nonobstetric) & Nongenital infections & I & I & 4 & 2 & 4 & 0 & 0 & $12(14.2)$ \\
\hline \multirow[t]{3}{*}{ causes } & Anemia & 2 & I & I & 0 & 2 & 0 & 0 & $6(7.1)$ \\
\hline & $\begin{array}{l}\text { Complications from } \\
\text { preexisting hypertension }\end{array}$ & 0 & I & 0 & 0 & 3 & I & 0 & $5(5.9)$ \\
\hline & Neoplasms & 0 & 0 & 0 & I & 0 & 0 & 0 & I (I.2) \\
\hline$N(\%)$ & & $12(14.3)$ & $14(16.6)$ & $20(23.8)$ & I3 (I5.5) & $20(23.8)$ & $4(4.7)$ & I (I.2) & $84(100.0)$ \\
\hline
\end{tabular}


Table 2 Distribution of the causes of maternal death by stage of pregnancy

\begin{tabular}{|c|c|c|c|c|c|c|c|}
\hline \multirow[t]{2}{*}{ Category } & \multirow[t]{2}{*}{ Cause } & \multicolumn{6}{|c|}{ Stage of pregnancy, $n$} \\
\hline & & TI & T2 & T3 & Delivery & Postpartum period & $\mathbf{N}(\%)$ \\
\hline Direct (obstetric) & Obstetric hemorrhage & 0 & 4 & 4 & $\mathrm{I}$ & 17 & $26(30.9)$ \\
\hline \multirow[t]{3}{*}{ causes } & Complications of abortion & 9 & II & 0 & 0 & 0 & $20(23.8)$ \\
\hline & Preeclampsia/eclampsia & 0 & 0 & 3 & I & 3 & $7(8.3)$ \\
\hline & Complications of labor & 0 & 0 & 0 & 4 & 3 & $7(8.3)$ \\
\hline Indirect (nonobstetric) & Nongenital infections & 1 & 6 & 4 & 0 & 1 & $12(14.2)$ \\
\hline \multirow[t]{3}{*}{ causes } & Anemia & 1 & 3 & I & 0 & I & $6(7.1)$ \\
\hline & $\begin{array}{l}\text { Complications from } \\
\text { preexisting hypertension }\end{array}$ & 0 & 0 & 3 & 2 & 0 & $5(5.9)$ \\
\hline & Neoplasms & 0 & I & 0 & 0 & 0 & $\mathrm{I}(\mathrm{I} .2)$ \\
\hline N (\%) & & II (I3.I) & $25(29.8)$ & $15(17.8)$ & $8(9.5)$ & $25(29.8)$ & $84(100.0)$ \\
\hline
\end{tabular}

Notes: A statistically significant relationship was found between the timing of pregnancy and direct causes of maternal death $(P<0.00 \mathrm{I})$. The relationship between pregnancy and indirect causes of maternal death was not significant $(P>0.05)$.

Abbreviations: T1, first trimester; T2, second trimester; T3, third trimester.

uterine rupture (17.6\%), complications of preexisting hypertension (14.7\%), postabortion sepsis (14.7\%), postpartum hemorrhage (8.8\%), puerperal sepsis (5.8\%), anemic heart failure $(5.8 \%)$, and abruptio placentae $(2.9 \%)$.

\section{Discussion}

Direct (obstetric) causes accounted for the vast majority (71.4\%) of maternal deaths in this autopsy-based study, with obstetric hemorrhage accounting for a significant number of cases. In fact, obstetric hemorrhage was the single most frequent cause of maternal death overall. Also worthy of note is the fact that most postpartum hemorrhages were due to uterine atony, especially in high-risk women who belonged to the high-parity group. These women were also more likely to be in the older age groups. These findings are

Table 3 Specific causes of certain categories of maternal death

\begin{tabular}{lll}
\hline Category & Cause & N (\%) \\
\hline $\begin{array}{l}\text { Antepartum hemorrhage } \\
(\mathrm{n}=9)\end{array}$ & Abruptio placentae & $6(66.7)$ \\
& Ruptured uterus & I (II.I) \\
& Ruptured ectopic pregnancy I (II.I) \\
& Placenta previa & I (II.I) \\
Postpartum hemorrhage & Uterine atony & I3 (76.4) \\
$(\mathrm{n}=17)$ & Ruptured uterus & $2($ II.8) \\
& Retained placenta & $2($ II.8) \\
Complications of abortion & Septicemia & II $(55.0)$ \\
$(\mathrm{n}=20)$ & Hemorrhage & $5(25.0)$ \\
& Uterine perforation & $4(20.0)$ \\
Nongenital infections & Purulent meningitis & $5(41.7)$ \\
$(\mathrm{n}=12)$ & Pulmonary tuberculosis & $3(25.0)$ \\
& Pneumonia & $3(25.0)$ \\
& Tuberculous meningitis & I (8.3) \\
Complications from preexisting & Malignant hypertension & $2(40.0)$ \\
hypertension (n=5) & Left ventricular failure & $2(40.0)$ \\
& Intracranial hemorrhage & I (20.0) \\
\hline
\end{tabular}

in agreement with various studies conducted in other parts of Nigeria and in other developing countries. ${ }^{1,10,13-16}$ These facts reflect the poor state of the health care delivery system prevalent in these regions. It is therefore vital that improved management of the later stages of pregnancy, delivery, and postpartum period that takes into account well-defined risk factors and provides improved facilities to correctly treat these complications be made available, especially at the primary care level. This is pertinent because most cases of maternal deaths in the tertiary care centers in Nigeria are those referred from various poorly equipped primary care centers. ${ }^{2}$ Interestingly, the frequencies of puerperal sepsis and preeclampsia/eclampsia were quite low when compared with the other causes of obstetric deaths.

Also noteworthy is the high proportion $(23.8 \%)$ of complications resulting from unsafe induced abortion. Complications of unsafe abortion remain a major cause of maternal mortality in developing countries, due to the fact that abortion is illegal in most of such countries, including Nigeria. The types of complications arising from these unsafe (and illegal) abortions (septicemia, severe hemorrhage, uterine perforation) suggest that these procedures were performed either by unqualified personnel or carried out in inappropriate care centers. This is buttressed by the fact that most of the affected women in this study were young ( $<25$ years of age) and unmarried dependents. ${ }^{17,18}$

Overall, the results of this study suggest that infectious diseases contribute significantly to maternal mortality, constituting $33.3 \%$ of cases. A significant proportion of these were due to infections not directly related to the pregnancy (nongenital infections). These nongenital infections accounted for $50.0 \%$ of all nonobstetric or indirect maternal deaths (and $14.2 \%$ of all maternal deaths) and included easily 


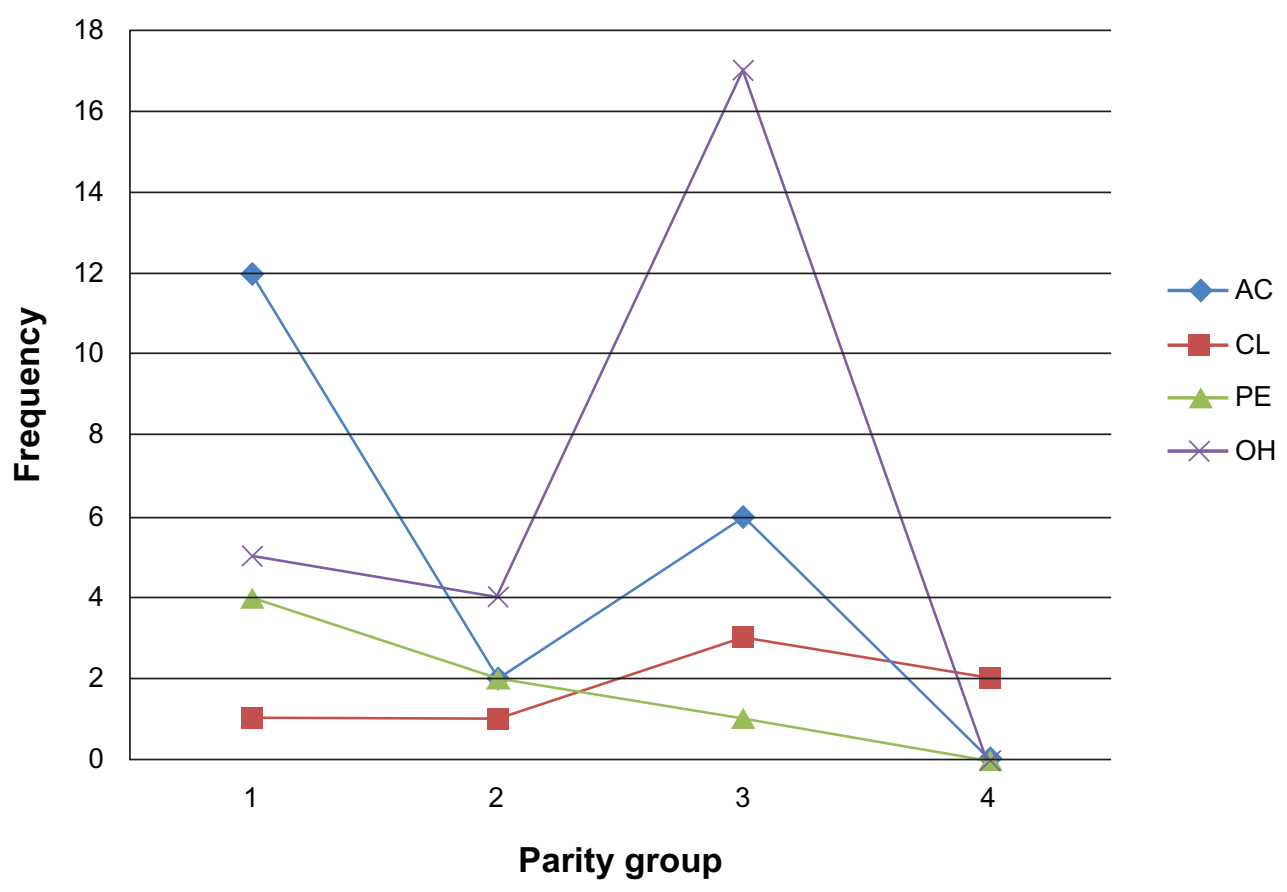

Figure I Parity in relation to the direct causes of maternal death.

Notes: Parity groups: I, Nullipara (never given birth); 2, Para I (given birth one time); 3, Para 2-4 (given birth two, three, or four times); 4, >Para 4 (given birth more than four times). Obstetric hemorrhage and complications of labor were more common among Para 2-4 individuals, whereas the complications of abortion and preeclampsia/ eclampsia were more common in the Nullipara group ( $P=0.009)$.

Abbreviations: $\mathrm{AC}$, complications of abortion; $\mathrm{CL}$, complications of labor; $\mathrm{PE}$, preeclampsia/eclampsia; $\mathrm{OH}$, obstetric hemorrhage.

treatable conditions, some of which are typically associated with low case-fatality rates. The prompt diagnosis and treatment of infectious diseases during pregnancy may thus have a significant impact on reducing maternal mortality in this environment.

Direct or obstetric causes of maternal deaths, unlike the indirect causes, are well-known to be associated with increasing maternal age, parity, and the stage of the pregnancy, as these factors have direct physiological effects on the outcomes of the pregnancies. ${ }^{3,6,19,20}$ These facts were corroborated by this study, which showed that complications from unsafe abortions and pregnancy-induced hypertension were more common in the younger age group, whereas obstetric hemorrhages were more common in women older than 25 years of age and in the third trimester. Although complications from unsafe abortions and ectopic pregnancy were more common in the first and second trimesters, complications associated with pregnancy-induced hypertension were more likely in the later stages of pregnancy.

Poverty and poor education are well-known to contribute significantly to maternal mortality. In this study, $70.0 \%$ of maternal deaths occurred among the unskilled, unemployed, and student populations. ${ }^{21,22}$ This may explain why many of these women did not receive any proper form of antenatal care, the lack of which is well-known to contribute significantly to maternal mortality. Our study showed that $67.0 \%$ of the women did not receive antenatal care and were seen for the first time when they presented with various complications. ${ }^{3,23}$

In the developing world, where maternal mortality rates are highest, the leading causes of death are well-known. Nevertheless, complex disease processes with uncertain pathogenesis and clinical presentations can pose a problem for accurate death certification, even in developed countries. These may adversely affect the accuracy of the relevant data on maternal mortality, with the attendant consequences on efforts geared at reducing it. Thus, maternal autopsies are required for accurate death certification and determination of the actual underlying causes of death. ${ }^{6}$ Our study showed discrepancies between the clinical and autopsy-based diagnoses in $38.1 \%$ of cases. These discrepancies cut across all of the various causes of maternal death. This greatly underscores the importance of maternal autopsies in making accurate diagnoses with the attendant consequences for the prevention and reduction of maternal deaths, which have been well-documented in many developed countries. ${ }^{6}$

The maternal mortality rate observed in this study ( 1,713 deaths per 100,000 live births) is much higher than the Nigerian national average, which ranges between 165 deaths per 100,000 live births in the southwest region 
to 1,549 deaths per 100,000 live births in the northeastern subregions of the country. Similarly, results from this study may not accurately reflect the entire community, because the study center (OAUTHC) is at the highest referral level for the country. Nevertheless, this study underscores the poor state of Nigeria's health care delivery system. Efforts should therefore be mobilized to ensure great improvement in the nearest future.

\section{Acknowledgments}

We wish to acknowledge the input of Professor Olusegun Fatusi on the statistical aspect of the work and the staff members of the Department of Morbid Anatomy and Forensic Medicine, Obafemi Awolowo University Teaching Hospitals Complex, Ile-Ife, Nigeria for their encouragement and cooperation during the study.

\section{Disclosure}

The authors report no conflicts of interest in this work.

\section{References}

1. Menéndez C, Romagosa C, Ismail MR, et al. An autopsy study of maternal mortality in Mozambique: the contribution of infectious diseases. PLoS Med. 2008;5(2):e44.

2. Chama C, Mairiga A, Geidam A, Bako B. An assessment of policies and programs for reducing maternal mortality in Borno State, Nigeria. Afr J Reprod Health. 2010;14(3s1):49-54.

3. Uzoigwe SA, John CT. A ten year review of maternal mortality at PortHarcourt, Nigeria. Nig J Clin Pract. 2000;3(21):80-84.

4. Onwudiegwu $\mathrm{U}$. The effect of a depressed economy on the utilisation of maternal health services: the Nigerian experience II. J Obstet Gynaecol. 1997;17(2):143-148.

5. Chukudebelu WO, Ozumba BC. Maternal mortality in Anambra State of Nigeria. Int J Gynaecol Obstet. 1988;27(3):365-370.

6. Daramola AO, Banjo AA. Autopsy as a tool in the prevention of maternal mortality. Niger J Clin Pract. 2009;12(4):457-460.

7. Daramola AO, Elesha SO, Banjo AA. Medical audit of maternal deaths in the Lagos University Teaching Hospital, Nigeria. East Afr Med J. 2005;82(6):285-289.
8. Fubara DS, Ikimalo J, John CT. Pathology of maternal deaths in Rivers state (a ten year autopsy review) in a referral hospital. Niger Postgrad Med J. 2007;14(3):256-260.

9. Panchabhai TS, Patil PD, Shah DR, Joshi AS. An autopsy study of maternal mortality: a tertiary healthcare perspective. J Postgrad Med. 2009;55(1):8-11.

10. Kavatkar AN, Sahasrabudhe NS, Jadhav MV, Deshmukh SD. Autopsy study of maternal deaths. Int J Gynaecol Obstet. 2003;81(1):1-8.

11. World Health Organization. Maternal Mortality in 2005: Estimates Developed by WHO, UNICEF, UNFPA and the World Bank. Geneva, Switzerland: World Health Organization; 2007. Available from: http:// www.who.int/whosis/mme_2005.pdf. Accessed September 18, 2008.

12. Abramson JH, Gahlinger PM. Computer Programs for Epidemiologists: PEPI Version 3.01. Llanidloes, Wales: Brixton Books; 2001.

13. Geelhoed DW, Visser LE, Asare K, Schagen van Leeuwen JH, van Roosmalen J. Trends in maternal mortality: a 13-year hospital-based study in rural Ghana. Eur J Obstet Gynecol Reprod Biol. 2003;107(2): 135-139.

14. Kigbu JH, Daru PH, Ujah IA. Review of maternal deaths from unsafe abortion in Jos, Nigeria. Niger J Med. 2009;18(1):103-106.

15. Mairiga AG, Saleh W. Maternal mortality at the State Specialist Hospital Bauchi, Northern Nigeria. East Afr Med J. 2009;86(1):25-30.

16. Olatunji AO, Sule-Odu AO. Maternal mortality at Sagamu, Nigeria - a ten year review (1988-1997). Niger Postgrad Med J. $2001 ; 8(1): 12-15$.

17. Xu J, Kochanek KD, Murphy SL, Tejada-Vera B. National Vital Statistics Reports. Deaths: Final Data for 2007. Hyattsville, MD: National Center for Health Statistics; 2010. Available from: http:// www.nber.org/mortality/2007/nvsr58_19.pdf. Accessed October 10, 2013.

18. Berg CJ, Callaghan WM, Syverson C, Henderson Z. Pregnancyrelated mortality in the United States, 1998 to 2005. Obstet Gynecol. 2010;116(6):1302-1309.

19. Fasubaa OB, Ogunniyi SO, Ezechi OC. Maternal mortality in Obafemi Awolowo University Teaching Hospitals Complex, Ile Ife, Nigeria: a comparism of maternal death in youth and the old. Niger J Med. 1999;8(4):147-151.

20. Ezechi OC, Fasubaa OB, Dare FO. Abortion related deaths in south western Nigeria. Niger J Med. 1999;8(3):112-114.

21. Ronsmans C, Graham WJ; Lancet Maternal Survival Series steering group. Maternal mortality: who, when, where, and why. Lancet. 2006;368(9542):1189-1200.

22. Harrison KA. The struggle to reduce high maternal mortality in Nigeria. Afr J Reprod Health. 2009;13(3):9-20.

23. Tucker MJ, Berg CJ, Callaghan WM, Hsia J. The Black-White disparity in pregnancy-related mortality from 5 conditions: differences in prevalence and case-fatality rates. Am J Public Health. 2007;97(2):247-251.
International Journal of Women's Health

\section{Publish your work in this journal}

The International Journal of Women's Health is an international, peerreviewed open-access journal publishing original research, reports, editorials, reviews and commentaries on all aspects of women's healthcare including gynecology, obstetrics, and breast cancer. The manuscript management system is completely online and includes

\section{Dovepress}

a very quick and fair peer-review system, which is all easy to use. Visit http://www.dovepress.com/testimonials.php to read real quotes from published authors. 